\title{
Combustion Behavior of Pulverized Coal in a Raceway Cavity of Blast Furnace and Its Application to a Large Amount Injection
}

\author{
Yotaro OHNO, Takeshi FURUKAWA ${ }^{1)}$ and Masahiro MATSU-URA ${ }^{1)}$ \\ Planning and Coordination Department, Research and Development Division, NKK Corporation, Marunouchi, Chiyoda-ku, \\ Tokyo, 100 Japan. $\quad$ 1) Materials and Processing Research Center, NKK Corporation, Minamiwatarida-cho, Kawasaki-ku, \\ Kawasaki, Kanagawa-ken, 210 Japan.
}

(Received on December 28, 1993; accepted in final form on May 25, 1994)

For a large amount of pulverized coal injection into a blast furnace, the combustion of pulverized coal in a raceway cavity has been studied theoretically and experimentally.

The theoretical formula, which can estimate the combustion efficiency of pulverized coal in a raceway cavity, were derived. The effects of the injecting and operation conditions on the limit of pulverized coal combustion in a raceway cavity were evaluated.

The effect of mixing of pulverized coal with oxygen on the combustion rate of pulverized coal was studied in a combustion test using both empty and coke packed furnace. From the results, the validity of the derived theoretical equation was verified, and it was also confirmed that the making sure of a raceway depth and the adoption of a injection technique which promotes the mixing of pulverized coal with oxygen are important to promote the combustion of pulverized coal.

Based on these discussions, the upper limit of pulverized coal injection rate in the hot blast furnace operation was estimated. To inject a large amount of pulverized coal more than the actually accomplished amount, it is necessary to increase the oxygen concentration in blast and adopt a injection technique which promote the mixing of pulverized coal with oxygen.

KEY WORDS: blast furnace; pulverized coal; injection; oxygen; combustion; raceway.

\section{Introduction}

The pulverized coal injection into a blast furnace is being used on a global scale to improve the stability and reduce the cost of blast furnace operations. Furthermore, many coke ovens have become too old for work and the time has arrived for their replacement. Under these circumstances, replacing the large amount of the coke currently used with pulverized coal is very significant, especially from the view point of economics. Much attention has been directed to a large amount of pulverized coal injection into a blast furnace. ${ }^{1-3)}$

In order to inject a large amount of pulverized coal into a blast furnace, a high combustion load of pulverized coal in the raceway is essential. The combustion characteristics of pulverized coal in the raceway must be clarified to allow a suitable injection method to be selected based on its ability to inject a large amount of coal.

Narita et al., ${ }^{4)} \mathrm{Kaku}$ et $a .^{5)}$ and Takeda et al. ${ }^{6}$ developed a one-dimensional combustion model of pulverized coal combustion in the raceway. However, they did not take the mixing process of pulverized coal and oxygen into account, and the effects of mixing cannot be evaluated under high pulverized coal-oxygen ratios. Therefore, the model is not considered adequate for applying to the current case.

This paper describes the results of studies on the theory of pulverized coal combustion in the raceway, the effects of operational conditions on combustion, the effect of mixing of the pulverized coal and oxygen on combustion and the maximum rate of pulverized coal injection in a commercial blast furnace.

\section{Theoretical Basis of Pulverized Coal Combustion in Raceway}

\subsection{Size of Raceway Cavity as Combustion Zone}

A schematic representation of a raceway and a cavity formed in the front of a tuyere is shown in Fig. 1. Because of the low ratio of coke present in this cavity, any injected pulverized coal is burnt in preference to coke. Therefore, it is of critical importance that a stable raceway cavity is maintained and is as large as possible.

The following equations are used to estimate the depth of a raceway cavity. ${ }^{7)}$ These equations were derived from a wide range of conditions that include the range from hot blast blowing of commercial blast furnaces to model experiments carried out by blowing at normal temperatures. Using the equations, the gas velocity at the tuyere tips can be calculated from the bosh gas flow rate and temperature. 


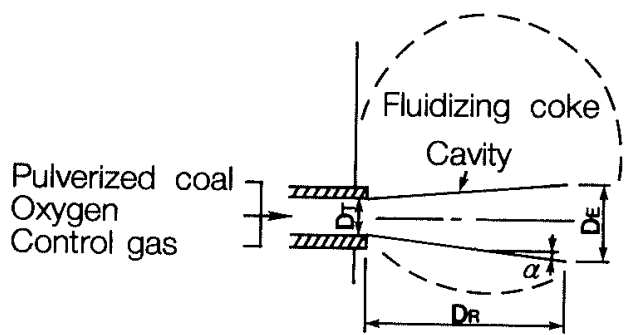

Fig. 1. Concept of combustion zone of pulverized coal in the raceway.

$$
\frac{D_{R}}{D_{T}}=0.521 \cdot\left(\sqrt{\frac{\rho_{g b}}{\rho_{C}}} \cdot \frac{U_{0 b}}{\sqrt{g \cdot D_{C}}}\right)^{0.8}
$$

where, $D_{R}$ : Raceway depth (m)

$D_{T}:$ Tuyere diameter $(\mathrm{m})$

$U_{0 b}$ : Gas velocity at tuyere tip referred to bosh gas $(\mathrm{m} / \mathrm{s})$

$D_{C}:$ Coke diameter $(\mathrm{m})$

$\rho_{C}:$ Apparent density of coke $\left(\mathrm{kg} / \mathrm{m}^{3}\right)$

$\rho_{g b}:$ Gas density referred to bosh gas $\left(\mathrm{kg} / \mathrm{m}^{3}\right)$

$g$ : Acceleration of gravity $\left(\mathrm{m} / \mathrm{s}^{2}\right)$.

For a raceway cavity that is assumed to be a truncated cone spreading out from the tuyere tip at angle $\alpha$, the volume $V_{f}$ is calculated from the following equation:

$$
\begin{gathered}
V_{f}=\pi / 12 \cdot D_{R} \cdot\left(D_{T}^{2}+D_{T} \cdot D_{E}+D_{E}^{2}\right) \\
D_{E}=D_{T}+2 \cdot \tan \alpha \cdot D_{R}
\end{gathered}
$$

where, $V_{f}:$ Volume of raceway cavity $\left(\mathrm{m}^{3}\right)$

$D_{E}$ : Diameter of raceway cavity tip (m).

\subsection{Formulation of Combustion Rate of Pulverized Coal in Raceway Cavity}

A simple model was developed by making the following assumptions on the combustion of pulverized coal in the raceway cavity:

(1) The raceway cavity is surrounded by high temperature coke. The temperature of the gas and pulverized coal is constant and equal to the theoretical flame temperature. The gas pressure is constant.

(2) The particle diameter and density in the combustion process are constant.

(3) Coke combustion is neglected comparing with pulverized coal combustion.

(4) A combustion reaction at the surface of fine carbon particle like pulverized coal is mainly $\mathrm{C}+$ $1 / 2 \mathrm{O}_{2}=\mathrm{CO}$ at high temperature. ${ }^{8)}$ Therefore, only $\mathrm{C}+1 / 2 \mathrm{O}_{2}=\mathrm{CO}$ is considered as a combustion reaction.

(5) The combustion gas flow is constant and equal to the post combustion value of pulverized coal.

The combustion rate $R$ per unit combustion space is obtained with the following equation by multiplying the density of the pulverized coal in the space and the specific surface area per unit weight of pulverized coal by the combustion reaction rate for a single pulverized coal particle.

$$
R=\frac{W_{s}}{V_{g}} \cdot \frac{6}{\rho_{P} \cdot D_{P}} \cdot K \cdot C_{\mathrm{O}_{2}}
$$

where, $R$ : Combustion rate per unit volume

$$
\left(\mathrm{kmol}-\mathrm{O}_{2} / \mathrm{m}^{3} \cdot \mathrm{s}\right)
$$

$W_{s}:$ Flow rate of pulverized coal $(\mathrm{kg} / \mathrm{s})$

$V_{g}:$ Gas flow rate $\left(\mathrm{m}^{3} / \mathrm{s}\right)$

$\rho_{P}:$ Apparent density of pulverized coal $\left(\mathrm{kg} / \mathrm{m}^{3}\right)$

$D_{P}:$ Diameter of pulverized coal $(\mathrm{m})$

$K$ : Overall rate constant $(\mathrm{m} / \mathrm{s})$

$C_{\mathrm{O}_{2}}$ : Mole concentration of oxygen in combustion space $\left(\mathrm{kmol}-\mathrm{O}_{2} / \mathrm{m}^{3}\right)$.

The rate of change of the oxygen content per unit time corresponds the combustion rate and is obtained by the following equation, assuming that the gas flow rate is constant.

$$
-\frac{d C_{\mathrm{O}_{2}}}{d \theta}=R=A \cdot C_{\mathrm{O}_{2}}
$$

where, $\quad A=\frac{W_{s}}{V_{g}} \cdot \frac{6}{\rho_{P} \cdot D_{P}} \cdot K$

$\theta:$ Time (s)

When assuming $C_{\mathrm{O}_{2}}=\left(C_{\mathrm{O}_{2}}\right)_{0}$ at $\theta=0$, Eq. (4) becomes $C_{\mathrm{O}_{2}} /\left(C_{\mathrm{O}_{2}}\right)_{0}=\exp (-A \cdot \theta)$. Therefore, it may be approximated by $\exp (-A \cdot \theta) \fallingdotseq 1-A \cdot \theta$ in the range where $A \cdot \theta$ is small.

$$
C_{\mathrm{O}_{2}} /\left(C_{\mathrm{O}_{2}}\right)_{0}=1-A \cdot \theta
$$

The quantity of reaction oxygen during its retention time in the raceway cavity becomes $V_{g}\left(\left(C_{\mathrm{O}_{2}}\right)_{0}-C_{\mathrm{O}_{2}}\right)$ $\left(\mathrm{kmol}-\mathrm{O}_{2} / \mathrm{s}\right)$, on the assumption that the gas flow is constant. The quantity of carbon that enters the raceway cavity is $W_{s} \cdot E_{c} / 12(\mathrm{kmol}-\mathrm{C} / \mathrm{s})$ by assuming that the content of carbon in pulverized coal is $E_{C}(-)$. Therefore, the combustion ratio $\eta(-)$ of the pulverized coal in the raceway cavity can be expressed by the following equation:

$$
\eta=\frac{2 \cdot V_{g}\left(\left(C_{\mathrm{O}_{2}}\right)_{0}-C_{\mathrm{O}_{2}}\right)}{\frac{W_{S} \cdot E_{C}}{12}}
$$

For a retention time of pulverized coal in the raceway cavity equal to $\tau$, Eq. (7) is obtained from Eqs. (5) and (6):

$$
\eta=\frac{24}{E_{C}} \cdot \frac{6}{D_{\mathrm{p}} \cdot \rho_{P}} \cdot K \cdot \tau \cdot\left(C_{\mathrm{O}_{2}}\right)_{0}
$$

Where $\tau$ is obtained from the ratio of the volume of raceway cavity $V_{f}$ to gas flow rate $V_{g}$ :

$$
\tau=V_{f} / V_{g}
$$

The oxygen concentration $\left(C_{\mathrm{O}_{2}}\right)_{0}$ is defined by using the inflow gas rate $\left(V_{g}\right)_{0}$ :

$$
\left(C_{\mathrm{O}_{2}}\right)_{0} \cdot V_{g}=\left(C_{\mathrm{O}_{2}}\right)_{00} \cdot\left(V_{g}\right)_{0}
$$

where, $\left(C_{\mathrm{O}_{2}}\right)_{00}$ : Oxygen concentration of inflow gas $\left(\mathrm{kmol}-\mathrm{O}_{2} / \mathrm{m}^{3}\right)$.

The combustion gas flow rate $V_{g}$ varies with the inflow gas rate $\left(V_{g}\right)_{0}$, changes in temperature and the gas mol number. When the inflow gas temperature is assumed as $T_{0}(\mathrm{~K})$, the pulverized coal-oxygen ratio as $X(\mathrm{~kg}$ coal $\left./ \mathrm{Nm}^{3}-\mathrm{O}_{2}\right)$, and the ultimate analysis $(\mathrm{C}, \mathrm{H}, \mathrm{N}, \mathrm{O}$, S) (dry basis) as $E_{C}, E_{H}, E_{N}, E_{O}$ and $E_{S}(-)$, respectively, the gas flow ratio $\left(V_{g}\right)_{0} / V_{g}$ is expressed by the 
following equation. Here, the chemical composition of the produced gas is assumed to be $\mathrm{CO}, \mathrm{H}_{2}, \mathrm{~N}_{2}$ and $\mathrm{H}_{2} \mathrm{~S}$.

$$
\frac{\left(V_{g}\right)_{0}}{V_{g}}=\frac{1}{1+B \cdot\left(Y_{\mathrm{O}_{2}}\right)_{0} \cdot X} \cdot \frac{T_{0}}{T}
$$

where, $B=22.4 \cdot\left(E_{O} / 32+E_{C} / 24+E_{H} / 2+E_{N} / 28\right)$

$\left(Y_{\mathrm{O}_{2}}\right)_{0}$ : Oxygen mole fraction of inlet gas $(-)$

$T$ : Temperature in raceway cavity $(\mathrm{K})$,

where,

$$
\left(C_{\mathrm{O}_{2}}\right)_{00}=\frac{P}{R_{g} \cdot T_{0}} \cdot\left(Y_{\mathrm{O}_{2}}\right)_{0}
$$

$P: \quad$ Pressure in raceway cavity (atm)

$R_{g}$ : Gas constant $\left(=0.082054 \mathrm{~m}^{3} \cdot \mathrm{atm} / \mathrm{K} \cdot \mathrm{kmol}\right)$.

The following equation for estimating the combustion ratio of pulverized coal in the raceway cavity is derived from Eqs. (7), (9), (10) and (11):

$$
\eta=\frac{24}{E_{C} \cdot R_{g}} \cdot \frac{6}{D_{P} \cdot \rho_{P}} \cdot \frac{1}{1+B \cdot\left(Y_{\mathrm{O}_{2}}\right)_{0} \cdot X} \cdot\left(Y_{\mathrm{O}_{2}}\right)_{0} \cdot \frac{P}{T} \cdot K \cdot \tau
$$

While the pulverized coal-oxygen ratio $X$ is a practical parameter, numerical values differ with the chemical composition of the pulverized coal. The value $X_{C}$, when pulverized coal is completely burned to $\mathrm{CO}_{2}, \mathrm{H}_{2} \mathrm{O}$, and $\mathrm{SO}_{2}$, and the value $X_{G}$, when completely gasified to $\mathrm{CO}, \mathrm{H}_{2}$, and $\mathrm{H}_{2} \mathrm{~S}$ are calculated using the following equations:

$$
\begin{gathered}
X_{C}=1 / 22.4 /\left(E_{C} / 12+E_{H} / 4+E_{S} / 32-E_{o} / 32\right) \\
X_{G}=1 / 22.4 /\left(E_{C} / 24-E_{o} / 32\right) \ldots \ldots \ldots . .
\end{gathered}
$$

For example, the values for Witbank coal become $X_{C}=0.630$ and $X_{G}=1.572$ at $E_{C}=0.74, E_{H}=0.046$, $E_{O}=0.078$, and $E_{S}=0.0053$. The values do not indicate large differences between the common coal grades, which have values of about 0.65 and 1.6 for $X_{C}$ and $X_{G}$, respectively.

\subsection{Rate Constant and Rate-controlling Process}

The combustion reaction of pulverized coal particles is comprised of three processes: chemical reaction, gas film diffusion on the particle surface and turbulent diffusion of the particles and oxygen. The overall rate constant is expressed by the following equations ${ }^{9}$ :

$$
\begin{gathered}
\frac{1}{K}=\frac{1}{K_{C}}+\frac{1}{K_{f}}+\frac{1}{K_{t}} \ldots \ldots \ldots . . . \\
K_{C}=6.5 \times 10^{5} \cdot T^{0.5} \cdot \exp (-22000 / T) \\
K_{f}=3.7 \times 10^{-5} /\left(D_{P} \cdot P\right)(T / 273)^{1.75} \ldots \\
K_{t}=3.6 \times 10^{-2} \cdot V \cdot \rho_{P} \cdot D_{P} \cdot U_{f} / D_{f} \ldots \ldots
\end{gathered}
$$

where, $K_{C}$ : Rate constant for chemical reaction $(\mathrm{m} / \mathrm{s})$

$K_{f}$ : Rate constant for boundary film diffusion $(\mathrm{m} / \mathrm{s})$

$K_{t}$ : Rate constant for turbulent diffusion $(\mathrm{m} / \mathrm{s})$

$V:$ Volume of combustion gas per unit weight of particle $\left(\mathrm{m}^{3} / \mathrm{kg}\right)$

$U_{f}$ : Average velocity of combustion flame $(\mathrm{m} / \mathrm{s})$

$D_{f}$ : Average diameter of combustion flame (m).

where $V, U_{f}$ and $D_{f}$ are obtained from the following equations:

$$
\begin{aligned}
& V=V_{g} / W_{S} \\
& U_{f}=D_{R} / \tau \ldots \ldots \ldots \ldots \ldots \ldots \ldots \ldots \ldots \ldots \ldots \ldots \\
& D_{f}=\left(4 \cdot V_{f} / D_{R} \cdot \pi\right)^{0.5}
\end{aligned}
$$

When Eq. (18) is rearranged by inserting Eqs. (10) and (19), an expression relating the coefficient of turbulent diffusion $K_{t}$ and the pulverized coal-oxygen ratio $X$ is obtained.

$$
\begin{aligned}
K_{t}= & F_{k} \cdot\left(3.6 \times 10^{-2}\right)\left(\rho_{P} \cdot D_{P}\right) \\
& \cdot \frac{U_{f}}{D_{f}} \cdot \frac{1+B \cdot\left(Y_{\mathrm{O}_{2}}\right)_{0} \cdot X}{\left(Y_{\mathrm{O}_{2}}\right)_{0} \cdot X} \cdot \frac{T}{273} \cdot \frac{1}{P}
\end{aligned}
$$

In order to express the mixing characteristics for a specific injection method, Eq. (18) is multiplied by a correction factor $F_{K} . F_{K}$ is experimentally determined.

The process that determines the combustion reaction rate is shown in Fig. 2. The equations given above are plotted in this figure with respect to the particle size of the pulverized coal and the temperature for the case of ratio $X_{C}$ (complete combustion of the specified pulverized coal-oxygen ratio). The solid lines indicate air combustion, and the broken lines show oxygen combustion. The two cases express the limits of each ratecontrolling process. The temperature of the raceway cavity is normally high, at $2000^{\circ} \mathrm{C}$ or more, indicating that the chemical reaction rate will be maintained at a sufficiently high level. It can be seen that the ratecontrolling processes are the mixed rate-controlling process of film and turbulent diffusion. Larger combustion flame gas flow velocity $U_{f}$ facilitate mixing. Therefore, the reaction rate for small particles is determined by film diffusion. When a comparison is made between air and oxygen combustion, the latter has a smaller combustion gas volume, and the effect of mixing

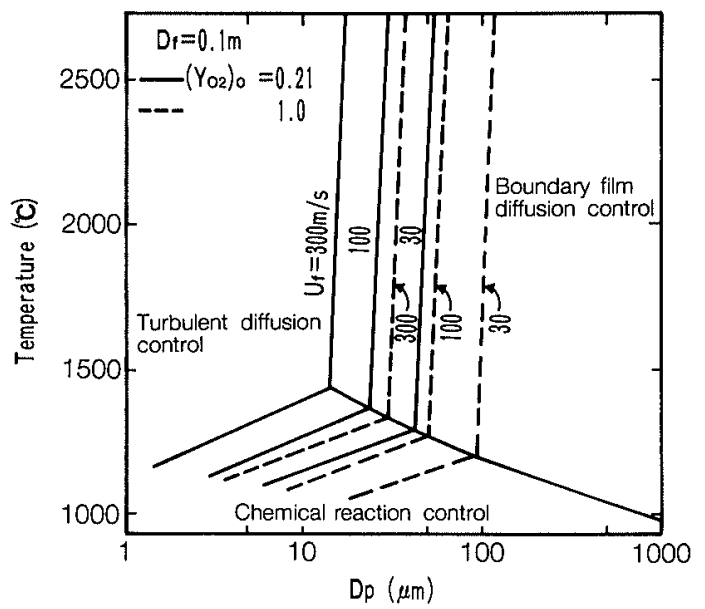

Fig. 2. Estimation of controlling factor of coal combustion in the raceway cavity. 


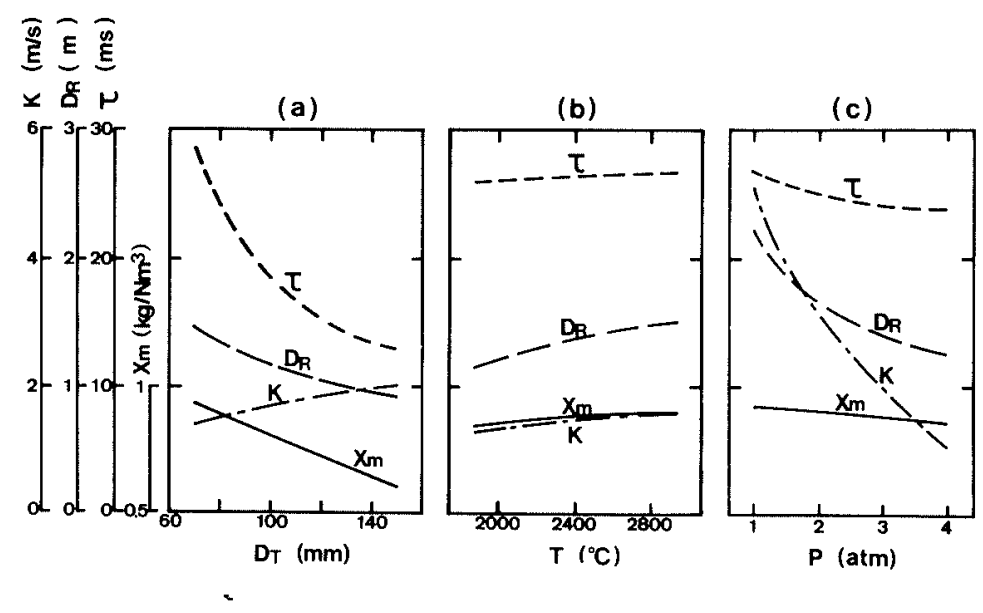

Fig. 3.

Effects of tuyere diameter, raceway temperature and gas pressure on pulverized coal combustion in the raceway cavity.

is small and the reaction rate for the larger particles is dominated by turbulent diffusion.

\subsection{Effect of Injection Conditions on Combustion Limitations}

The validity of Eq. (12) was verified by the combustion experiment using the coke packed furnace described later. In this chapter, it is described that the studied results of the effect of the injection condition on the combustion limitation of the pulverized coal in the raceway cavity, using Eq. (12).

According to Eq. (12), increasing the pulverized coal-oxygen ratio $X$ causes the combustion ratio $\eta$ to decrease. However, the combustion ratio $\eta$ is greater than 1 with $X$ raised to a value. This indicates that the combustion of pulverized coal in the raceway cavity has been completed. The limit $(\eta=1)$ for the pulverized coal-oxygen ratio is defined as the maximum combustible pulverized coal-oxygen ratio $X_{m}$. The limitations on pulverized coal injection are examined by studying its dependence on the tuyere diameter $D_{T}$, raceway cavity temperature $T$, pressure $P$, blast volume $\left(V_{g}\right)_{0}$, pulverized coal particle $D_{P}$ and blast oxygen molar fraction $\left(Y_{\mathrm{O}_{2}}\right)_{0}$.

The reference conditions were assumed as $D_{T}=0.08 \mathrm{~m}$, $T=2300^{\circ} \mathrm{C}, \quad P=3.5 \mathrm{~atm}, \quad\left(V_{g}\right)_{0}=90 \mathrm{Nm}^{3} / \mathrm{min}, \quad D_{P}=$ $50 \mu \mathrm{m},\left(Y_{\mathrm{O}_{2}}\right)_{0}=0.80$, and $F_{K}=1.0$.

The results are shown in Figs. 3 to 6 . The following points were obtained from these results.

(1) When the tuyere diameter $D_{T}$ is increased, the raceway depth $D_{R}$ decreases, and the retention time $\tau$ shortens. With an increase in the average flow velocity of the gas flow $U_{f}$ in the raceway cavity, the coefficient of turbulent diffusion $K_{t}$ increases, and the overall rate constant $K$ also rises slightly. However, $X_{m}$ is reduced because the effect of lowering the retention time is larger. (See Fig. 3(a).)

(2) When the raceway temperature is increased, the gas flow velocity $U_{f}$ is increased, and $D_{R}, \tau$ and $K$ also increase. However, $X_{m}$ increases only slightly because the molar concentration of oxygen decreases. Therefore, $X_{m}$ is assumed to remain constant within a raceway temperature range between 2000 and $2800^{\circ} \mathrm{C}$ (Fig. 3(b)) . Report $^{10)}$ of typical analytical results for conventional blast furnace operations with pulverized coal injection also indicated that the pulverized coal combustion efficiency has practically no dependence on raceway

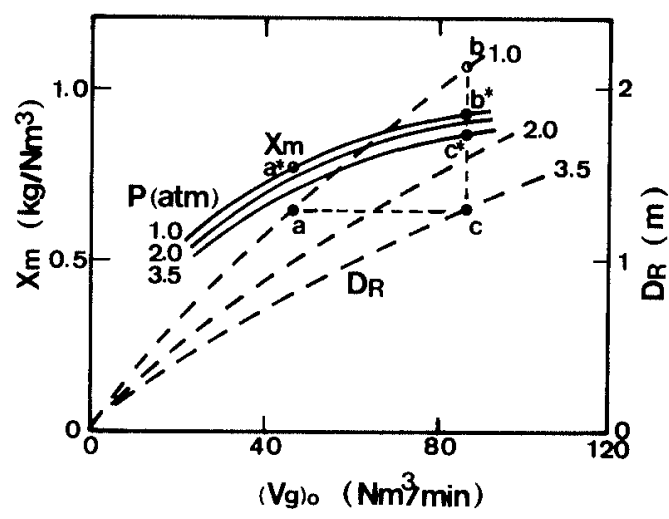

Fig. 4. Effect of blast rate on pulverized coal combustion in the raceway cavity.

temperature.

(3) When the pressure $P$ is raised, the diffusion rate decreases, but the molar concentration of oxygen increases proportionally. Therefore, the two effects cancel. Because the volume of the combustion space in the case of an empty furnace test ${ }^{11)}$ is constant, raising the pressure causes the gas flow velocity to decrease, extends the retention time and results in a rise of the combustion ratio. However, the reduction of the volume of the raceway cavity is larger than the effect of the reduced gas flow velocity. Therefore, the retention time $\tau$ is shortened. For this reason, $X_{m}$ lowered slightly. (See Fig. 3(c).)

(4) $D_{R}$ and $X_{m}$ are shown in Fig. 4 for the case of varying blast volume $\left(V_{g}\right)_{0}$ per tuyere. When the blast volume $\left(V_{g}\right)_{0}$ is increased under constant pressure, $D_{R}$ increases $(\mathrm{a} \rightarrow \mathrm{b}), \tau$ is lengthened, and $X_{m}$ also increases $\left(a^{*} \rightarrow b^{*}\right)$. In order to form a stable raceway cavity, it is necessary to control the depth $D_{R}$ within a certain range. Also in cases where the pressure is controlled so that $D_{R}$ becomes constant $(\mathrm{a} \rightarrow \mathrm{c}), X_{m}$ slightly increases $\left(\mathrm{a}^{*} \rightarrow \mathrm{c}^{*}\right)$ when the blast volume $\left(V_{g}\right)_{0}$ is raised. That is, when increasing the production rate, it can be thought that the combustion condition of the pulverized coal does not deteriorate. Conversely, when decreasing the production rate, it is essential to maintain the raceway depth $D_{R}$ by taking preventive measures such as lowering the pressure, reducing the tuyere diameter or decreasing the number of tuyeres to secure the necessary blast volume at each tuyere. 
(5) The coefficient of turbulent diffusion $K_{t}$ and the coefficient of film diffusion $K_{f}$ and $X_{m}$ for varying the pulverized coal particle diameter $D_{P}$ are shown in Fig. 5. When $D_{P}$ is decreased, $K_{f}$ increases proportionally with $D_{\vec{P}}^{-1}$, while $K_{f}$ decreases in direct proportion to $D_{P}$. According to the figure, the effect of $D_{P}$ reduction is outstanding when it is about $40 \mu \mathrm{m}$ or less. When the mixing characteristics of pulverized coal and oxygen which correspond to the injection method are poor (i.e., when $F_{K}$ is small), the effect of $K_{t}$ dominates, diminishing the $D_{P}$ reduction effect.

(6) In Fig. 6, $X_{m}$ is shown for varying oxygen molar fractions $\left(Y_{\mathrm{O}_{2}}\right)_{0}$ of the blast, and also shown the line of constant theoretical flame temperature $\left(T_{f}=2300^{\circ} \mathrm{C}\right)$. When $\left(Y_{\mathrm{O}_{2}}\right)_{0}$ is increased, $X_{m}$ is increased. The gas volume per pulverized coal particle is reduced with an increase in $\left(Y_{\mathrm{O}_{2}}\right)_{0}$ and in the pulverized coal-oxygen ratio $X$. Therefore, when mixing is poor and $F_{K}$ is small, $K_{t}$ is lowered, and the effect of an increase in $\left(Y_{\mathrm{O}_{2}}\right)_{0}$ decreases.

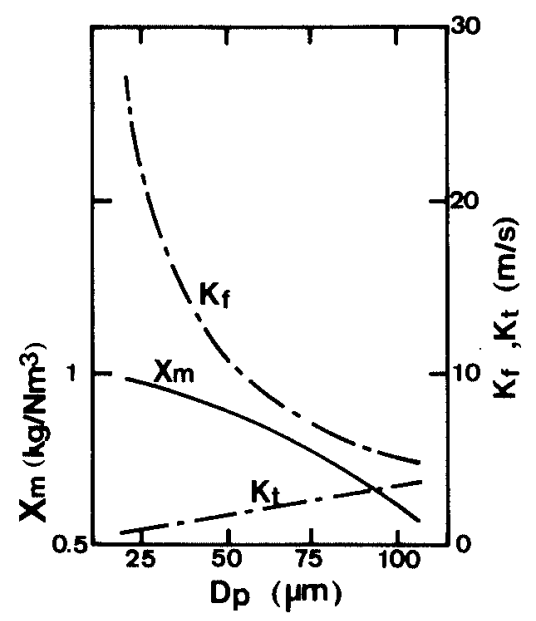

Fig. 5. Effect of coal diameter on pulverized coal combustion in the raceway cavity.

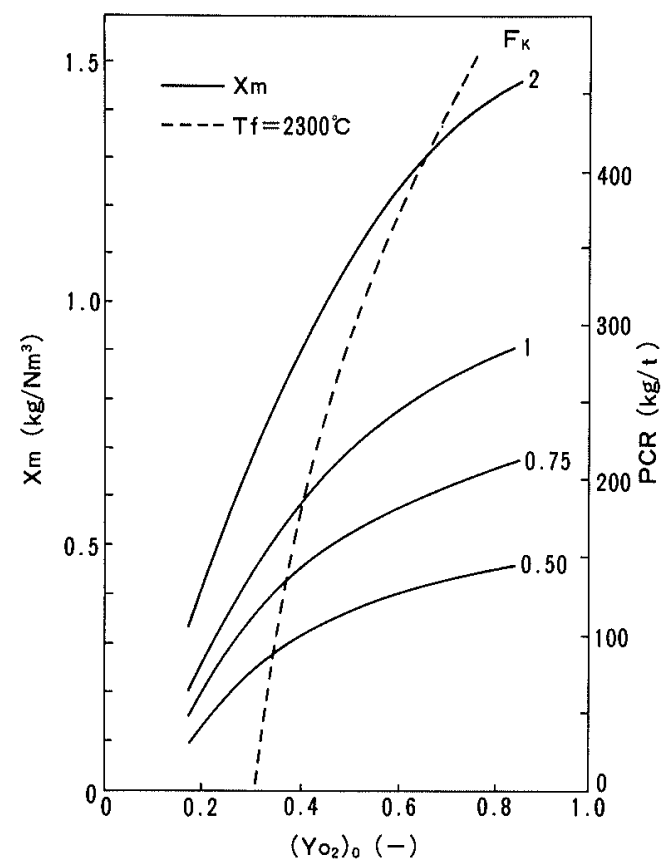

Fig. 6. Effect of oxygen mole fraction in blast on pulverized coal combustion in the raceway cavity.
When $F_{K}$ is large at $2, X_{m}$ increases practically in line with the increase in $\left(Y_{\mathrm{O}_{2}}\right)_{0}$. Therefore, it can be seen that injection technologies that are capable of attaining good mixing conditions (i.e., ensuring a large $F_{K}$ value) with increases in $\left(\mathrm{O}_{\mathrm{O}_{2}}\right)_{0}$ are important for achieving the injection of pulverized coal in a large quantity.

\section{Effect of Pulverized Coal and Oxygen Mixing Characteristics on Combustion Rate}

The pulverized coal and oxygen mixing process can be improved by optimizing the injection arrangement, (i.e., the burner structure). Therefore, combustion experiments were carried out to clarify the effect of the burner structure on the combustion conditions.

\subsection{Experimental Method}

As shown in Fig. 7, the test furnace is square with dimensions of $0.6 \mathrm{~m}$ wide, $1.5 \mathrm{~m}$ deep and $5.5 \mathrm{~m}$ high. The furnace walls were lined with refractory. One tuyere was used. A water-cooled probe was inserted from the opposite side of the tuyere to measure the temperature and to sample gas and dust. The furnace top had coke charging equipment and TV cameras to monitor the inside of the furnace. Combustion tests can be carried out with the furnace empty or filled with coke. Oxygen was supplied into the furnace at a maximum rate of $300 \mathrm{Nm}^{3} / \mathrm{h}$ and pulverized coal at a miximum rate of $200 \mathrm{~kg} / \mathrm{h} . \mathrm{CO}_{2}$ was used for adjusting the flame temperature and as a carrier gas, assuming the oxygen blast furnace process. Witbank coal was used for the

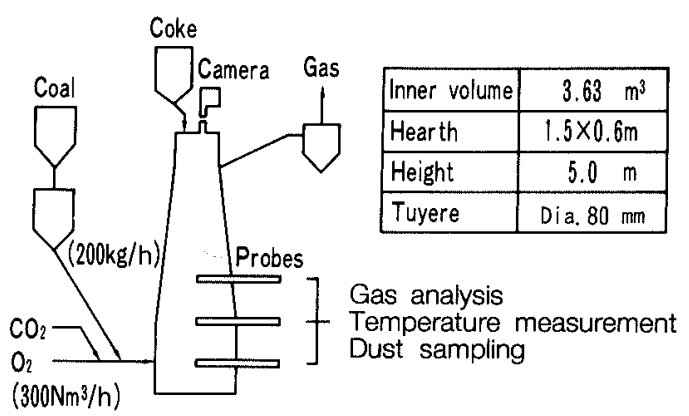

Fig. 7. Schematic diagram of shaft-type combustion furnace.
A. Coaxial burner $\left(D_{T}=20 \mathrm{~mm}\right)$
B. Coaxial burner $\left(\mathrm{Dr}_{\mathrm{r}}=35 \mathrm{~mm}\right)$
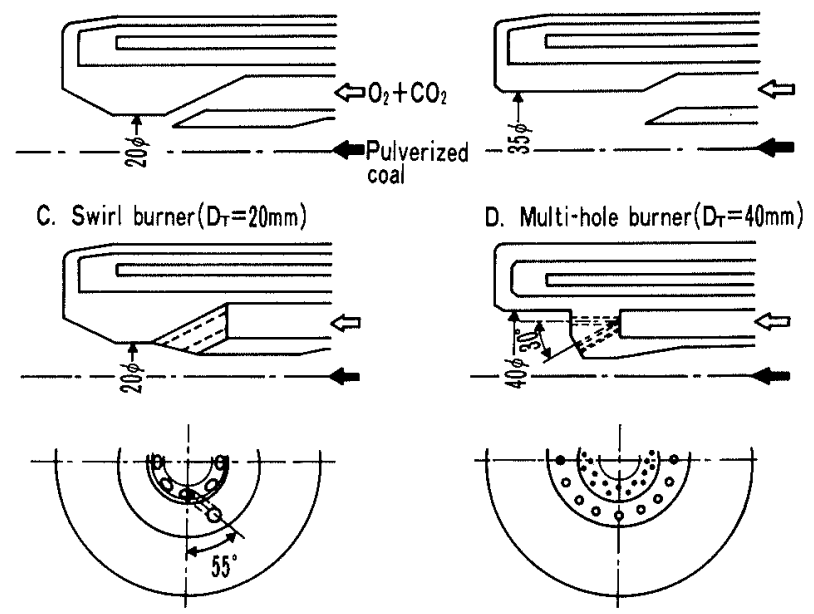

Fig. 8. Structure of burner head. 


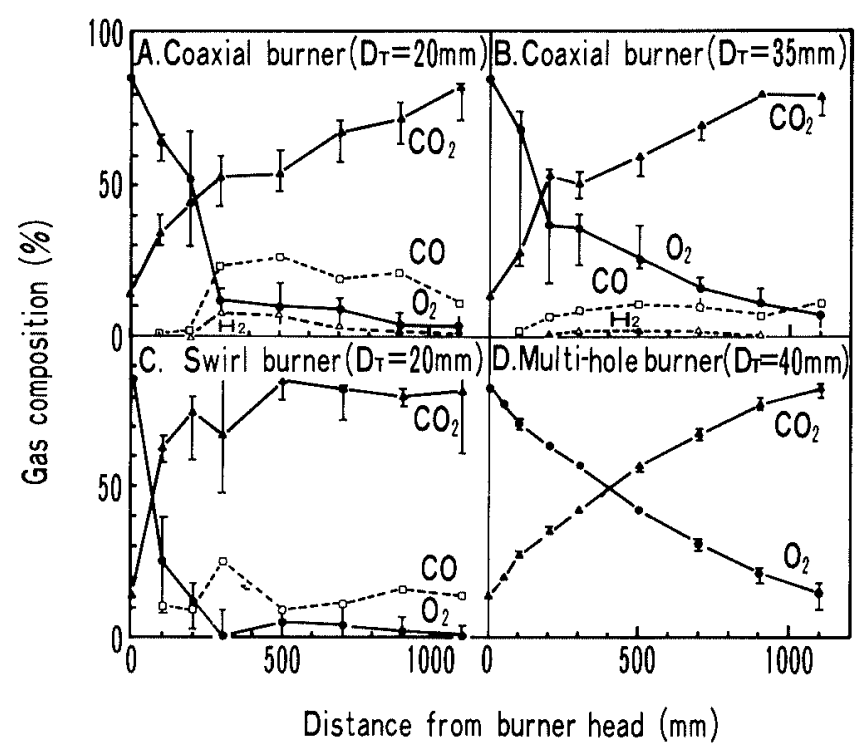

Fig. 9. Axial distribution of gas composition in combustion test. $\left(P C=100 \mathrm{~kg} / \mathrm{h}, P C / \mathrm{O}_{2}=0.5 \mathrm{~kg} / \mathrm{Nm}^{3}\right)$

pulverized coal. $80 \%$ of the particle sizes were made up of 200 mesh or less, with an average particle diameter of $50 \mu \mathrm{m}$.

The different burner tips used in the experiments are shown in Fig. 8. Burners A and B are coaxial types with different apertures. These burners are designed to carry out mixing action by the shearing force developed from the flow speed differential between oxygen and the pulverized coal. Burner $\mathrm{C}$ is a swirl type where mixing is promoted by the swirl of oxygen flow. Burner D is a multi-hole type burner that is designed to promote mixing of the oxygen and pulverized coal by blowing oxygen through perforations that force the gas into the pulverized coal flow and split it. The burner is inserted into the tuyere and fixed on the tuyere tip.

\subsection{Experimental Results under Empty Furnace Condi- tions}

Typical results of the combustion tests carried out in an empty furnace are shown in Fig. 9. The conditions were pulverized coal flow $=100 \mathrm{~kg} / \mathrm{h}$ and pulverized coal-oxygen ratio $=0.5 \mathrm{~kg} / \mathrm{Nm}^{3}$, which is less than 0.65 to provide excess oxygen. The figure shows the average gas composition and its fluctuation width.

The decrease in oxygen content is considered to indicate the progression of combustion from a macro point of view. The coaxial burner $A$ with its smaller aperture demonstrated a faster lowering of the oxygen content than burner B. The swirl type burner $\mathrm{C}$ showed a much faster lowering of the oxygen concentration compared to the coaxial type burner $A$ that has the same aperture. The oxygen content decrease pattern of the multi-hole type burner $\mathrm{D}$ was similar to the coaxial type burner B that has approximately the same aperture. On the other hand, fluctuations in the gas composition and the presence of $\mathrm{CO}$ and $\mathrm{H}_{2}$ are considered to indicate poor mixing from a micro point of view. For the multi-hole type burner $\mathrm{D}, \mathrm{CO}$ and $\mathrm{H}_{2}$ were not observed, and the micro-mixture can be seen to be superior to the other three types of burners.

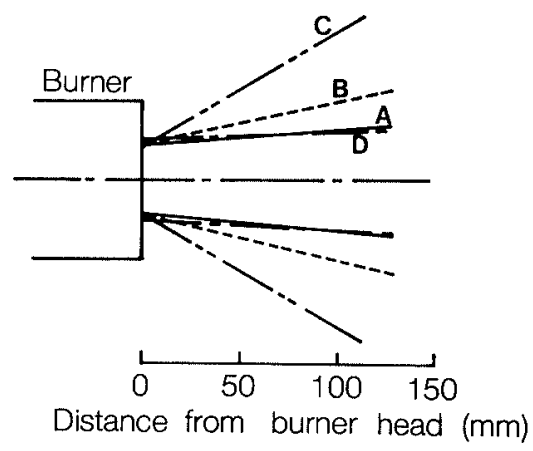

Fig. 10. Divergence of flame jet in the vicinity of burner head.

The spread of the flame jet at the burner tip as observed by the camera is shown in Fig. 10. For the coaxial type burner $\mathrm{A}$, the aperture is small and the spouting velocity is large. Therefore, the spread of the jet is small. In the case of the coaxial type burner B, however, the spread of the jet is slightly larger. The spread of the jet from the swirl type burner $C$ is larger because of the centrifugal force developed by the swirl. For the multi-hole type burner $\mathrm{D}$, the aperture is large, but the necessary amount of the axial direction momentum was ensured because of the higher velocity of oxygen blowing through the perforations. Therefore, there is practically no spread of the jet.

The combustion and flame jet spreading characteristics due to differences in burner structure correspond well to that of the state of raceway formation when the furnace is filled with coke, as discussed later.

\section{Formation of Raceway and Combustion in Raceway Cavity}

Combustion tests were carried out in the coke-packed bed to examine the raceway depth and the pulverized coal combustion rate, based on the theoretical equations.

\subsection{Experimental Method}

For the combustion test, the test furnace shown in Fig. 7 was filled with coke to a level of about $2 \mathrm{~m}$ above the tuyere. The coke particle diameters were between 15 and $25 \mathrm{~mm}$, with an average of $20 \mathrm{~mm}$, to maintain about the same ratio of particle diameter to tuyere diameter as a commercial furnace. Coke was charged based on periodic measurement of the charge level to maintain the coke bed at a constant height. The test was carried out without injecting pulverized coal only to investigate the raceway depth. The conditions were observed from behind the tuyere. The position where the tip of the probe inserted from the opposite side of the furnace began to appear was taken as the physical boundary of the raceway cavity. Furthermore, by arranging the burner tip position in the same location as the tuyere tip, the burner aperture was assumed to be the jet aperture of the tuyere tip.

\subsection{Experimental Results}

\subsubsection{Raceway Formation}

Changes in the raceway depth with burner aperture are shown in Fig. 11. The larger the aperture, the smaller the raceway depth was. For the swirl type burner $\mathrm{C}$, the 


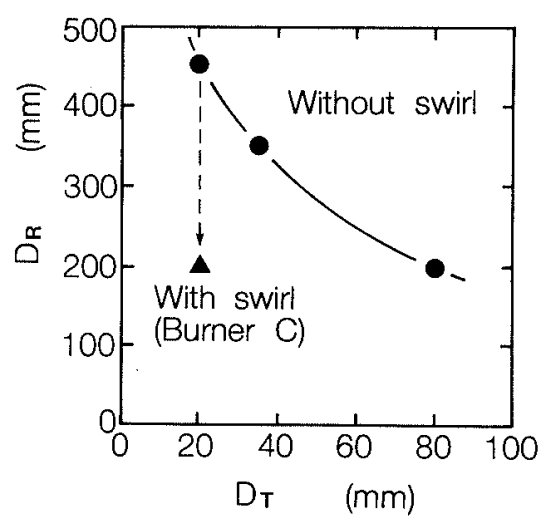

Fig. 11. Effect of diameter of burner out-let on raceway depth. -

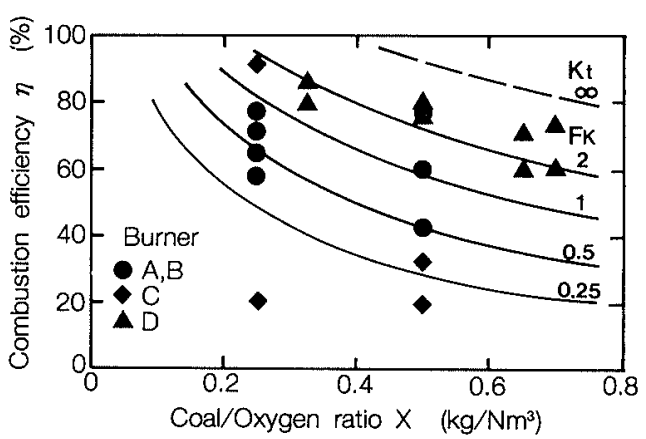

Fig. 12. Comparison of calculated combustion efficiencies and measured ones.

raceway depth was about half of that for the coaxial type burner with the same aperture. As shown in Fig. 10, this is considered to be due to the large spread angle (about $30^{\circ}$ ) of the swirl type burner jet, which causes faster damping of the gas flow velocity. The raceway depth is important to blast furnace operations for supplying coke to the raceway and reducing the heat load on the furnace body. Therefore, the decreased raceway depth from excessive swirl is undesirable.

\subsubsection{Pulverized Coal Combustion in the Raceway Cavity}

Combustion test results for the furnace filled with coke are shown in Fig. 12. On the whole, the combustion ratio tended to decrease as the amount of pulverized coal increased. The decrease was particularly large for the swirl type burner $C$, probably because of the shallow raceway depth and the short retention time of the pulverized coal. The multi-hole type burner $\mathrm{D}$ demonstrated good combustion characteristics. For a pulverized coal-oxygen ratio of about $0.6 \mathrm{~kg} / \mathrm{Nm}^{3}$, the combustion ratio was greater than $80 \%$. The effect of burner structure on the combustion results corresponded well to the results of the empty furnace test.

The calculated results from Eq. (12) are also shown in Fig. 12. Experimental results of each burner corresponded to the calculated results with constant $F_{K}$. Therefore, the validity of Eq. (12) was verified. The correction factor $F_{K}$, which indicates the mixing characteristics of each burner, can be evaluated by comparison of the test and calculated values. The multi-hole type burner $\mathrm{D}$ has a mixing characteristic of

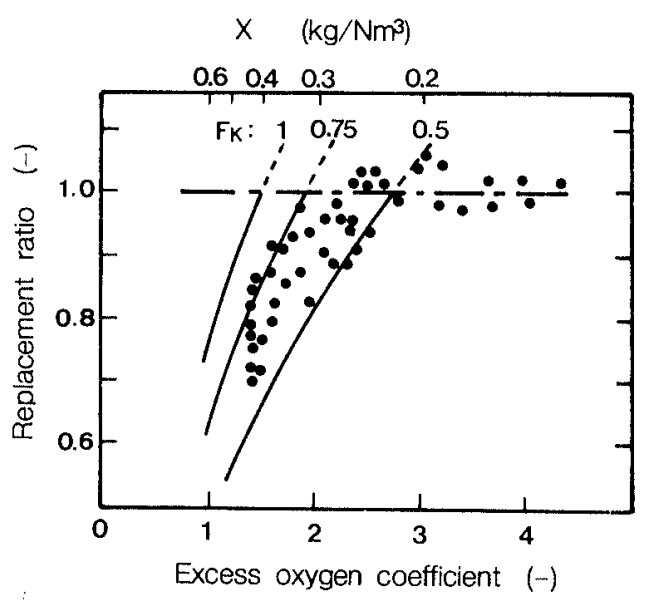

Fig. 13. Effect of excess oxygen coefficient on replacement ratio of pulverized coal to coke in a conventional blast furnace operation.

about $F_{K}=2$, while that of the coaxial type burners $\mathrm{A}$ and $\mathrm{B}$ are about $F_{K}=0.5$. The figure also shows the value for an infinite $K_{t}$. The performance of the multi-hole type burner D was found to be quite high when compared with that value.

Accordingly, since the combustion of pulverized coal in the raceway cavity is greatly affected by the burner structure, it is essential to use burners that mix the pulverized coal and oxygen effectively.

\section{Maximum Injectable Quantity of Pulverized Coal in Commercial Blast Furnaces}

Figure 13 shows the results to estimate how the replacement ratio of pulverized coal from coke changes when the excess oxygen ratio $\left(=X_{C} / X\right)$ is lowered. This was accomplished by increasing the quantity of pulverized coal injected into a commercial blast furnace. For a large excess oxygen ratio, the replacement rate is virtually constant at 1 , and pulverized coal is assumed to be burned completely. When the quantity of pulverized coal is increased, and the excess oxygen ratio is lowered, the replacement ratio decreases rapidly. Up to a certain quantity of injection at the least maximum injection quantity, $110 \mathrm{~kg} / \mathrm{t}$, in this operation, the calorific value of the top gas was found to increase without pulverized coal remaining as dust at the top. The reactivity of unburnt pulverized coal char is so high that it was probably consumed by reactions taking place in the furnace, such as solution loss reactions.

A mathematical model for pulverized coal combustion was evaluated, and the data plotted in the range of $F_{K}=0.75$ to 0.50 . Therefore, it can be assumed that these values indicate the mixing characteristics for the pulverized coal injection method in that blast furnace.

The relationship between the maximum injectable pulverized coal $X_{m}$ and the oxygen content in a commercial blast furnace was estimated, and the results are shown as broken lines in Fig. 14 in a manner similar to Fig. 6 . For $F_{K}=0.75$, the value of $X_{m}$ at $21 \%$ oxygen is about 0.25 . This indicates that the combustible quantity is about $60 \mathrm{~kg} / \mathrm{t}$. Therefore, a quantity exceeding that value must be consumed by reactions in the furnace. 


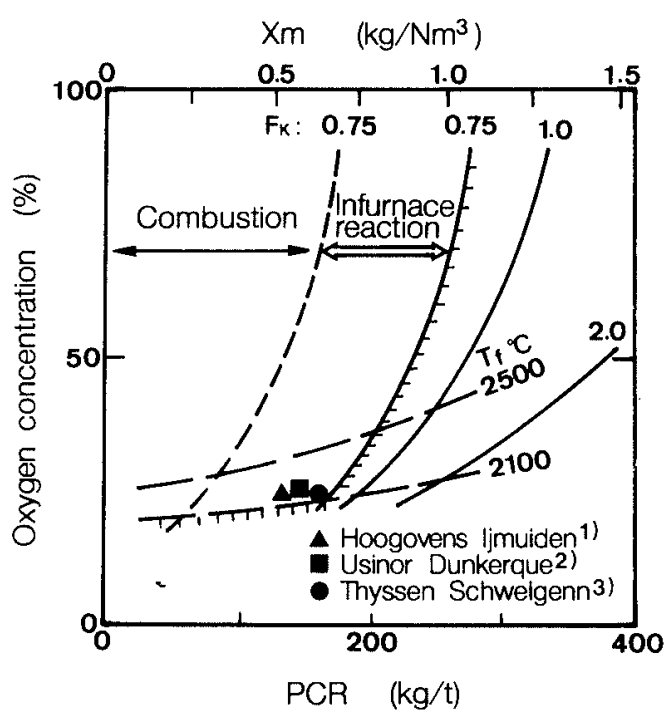

Fig. 14. Estimation of upper limit of pulverized coal injection rate in a conventional blast furnace operation.

Data for the actual maximum value of pulverized coal injection $^{1-3)}$ is indicated. The difference between that value and the combustible quantity is assumed to indicate limitations of the pulverized coal char consumption by reaction in the furnace. Therefore, the upper limit of the quantity of pulverized coal injection (solid lines) can be obtained by assuming that the quantity is about $90 \mathrm{~kg} / \mathrm{t}$.

Based on the figure, it is difficult to inject $300 \mathrm{~kg} / \mathrm{t}$ of pulverized coal at $F_{K}=0.75$, although it can be injected by raising $F_{K}$ to 1.0 and adjusting the oxygen content to about $65 \%$. In order to raise the quantity of pulverized coal injection at a lower oxygen concentration, it will be necessary to develop injection technology that is capable of increasing the mixing rate.

\section{Conclusions}

The combustion of pulverized coal in the raceway cavity was theoretically and experimentally examined. Based on the results, the limiting quantity of pulverized coal injection in a commercial blast furnace was analyzed, and the following conclusions were obtained.

(1) Equations for estimating the pulverized coal combustion ratio were derived. The combustion test results of a coke-packed bed were compared with the calculated combustion ratio, and the values were found to be consistent.

(2) The rate-controlling process for the combustion of pulverized coal in the raceway cavity is the mixed rate-controlling process of film and turbulent diffusion.

(3) The combustible pulverized coal-oxygen ratio in the raceway cavity is greatly affected by the retention time and turbulent diffusion of pulverized coal and oxygen. In order to inject pulverized coal in a large quantity, it is essential that the raceway depth is adequately maintained and that mixing of the pulverized coal and oxygen is effectively promoted.

(4) The parameter $F_{K}$ was introduced that expresses the mixing characteristics of pulverized coal and oxygen for the pulverized coal injection method. The pulverized coal combustion ratio can be improved by using an injection method that increases $F_{K} . F_{K}$ was 0.5 to 0.75 in the case of the normal method of injecting pulverized coal into a commercial blast furnace. $F_{K}$ was about 2 for a developed multi-hole type burner in this study.

(5) The effects of tuyere diameter, temperature, pressure, blast volume, pulverized coal particle diameter and oxygen concentration on the combustion ratio of pulverized coal in the raceway cavity were evaluated.

(6) While the effect of increasing the oxygen content in blast is large, it decreases when mixing of the pulverized coal and oxygen is poor.

(7) A study was made of the effect of $F_{K}$ and oxygen content on the limitations of pulverized coal injection in a commercial blast furnace. Injection at a rate of $300 \mathrm{~kg} / \mathrm{t}$ with $F_{K}=0.75$ is difficult, even if the oxygen concentration is increased. However, injection is possible at that rate when $F_{K}$ is raised to 1 for an oxygen concentration of about $65 \%$.

\section{REFERENCES}

1) W. Koen, R. B. Vogel, H. L. Toxopeus and G. A. Flierman: Proc. Ironmaking Conf., AIME, (1985), 437.

2) M. Guili, G. Hanniker, J. Koster, K. Kreibich, J. M. van Langen, Y. de Lassat de Pressigny and A. Poos: Proc. European Ironmaking Cong., (1989), IV-2.

3) K. H. Peters, W. Kowalski, B. Korthas and K. Kreibich: Proc. Ironmaking Conf. AIME, (1989), 819.

4) K. Narita, M. Maekawa, H. Kanayama, Y. Seki and T. Saito: Tetsu-to-Hagané, 68 (1982), 2385.

5) K. Kaku, M. Kuwabara and I. Muti: Tetsu-to-Hagané, 72 (1986), 1847

6) K. Takeda, S. Miyagawa and S. Taguchi: Proc. Ironmaking Conf. AIME, (1990), 455.

7) Y. Ohno, H. Hotta, M. Matsuura, M. Mitsufuji and H. Saito: Proc. Process Tech. Conf. AIME, (1988), 195.

8) K. Kobayashi and M. Okuyama: Kikai-no-Kenkyu, 10 (1958), 885 .

9) S. Yagi and D. Kunii: Proc. 5th Symp. Combustion, The Combustion Institute, (1955), 231.

10) T. Kato, S. Kishimoto, K. Kimura, A. Shimomura, T. Wada and Y. Ohno: NKK Tech. Rep., 115 (1986), 73.

11) H. Wakimoto, T. Sato, M. Fujiura and H. Hara: Tetsu-to-Hagané, 69 (1983), S105.

12) O. Charon, G. Prado, C. Offroy, M. Picard and J. L. Roth: Proc. European Ironmaking Cong., (1986), PIV-2.

(Originally published in Tetsu-to-Hagané, 78 (1992), 1, in Japanese) 